\title{
Ten Commandments for Special Collections Librarians in the Digital Age
}

THE SPEAKERS FOR "Rare and Special Bytes: Special Collections in the Digital Age," the 2008 Rare Books and Manuscripts Section Preconference, presented an exceptional array of ideas and opportunities for our profession to consider as we confront the challenges of the digital age. The sands are shifting under our feet on an almost daily basis. How to keep up and make the best decisions going forward? Are there any basic principles to guide us toward the most productive responses and actions?

In this paper I propose ten principles. I freely admit that "principles" is too grand a word-perhaps they're better as "sound bytes." Or Ten Commandments? Definitely too grandiose. But since they are stated in the affirmative, akin to "thou shalt" rather than "thou shalt not," perhaps they offer palatable food for thought. Regardless, these are ten simple ideas that have helped me move my own thinking forward as our professional world has progressed from being artifact-centered to one in which original objects will increasingly serve as "preservation originals." This is happening as our users increasingly want to access our materials remotely-and, thus, digitally. This is the case whether they are sophisticated scholars and researchers, students who are required to use primary sources for study and learning, or members of the broader human community who are attracted to, and frequently amazed by, the extraordinary objects that we so carefully curate and interpret.

A personal aside: Over the course of my career I have somehow managed to present, at the pace of roughly once per decade, several RBMS conference papers under the broad rubric of "thinking about technology." In 1986 I spoke of the utility of bringing "microcomputers" into special collections, described the introduction of a grand new invention known as the hard drive, and exhorted the audience to upgrade their desktops to $240 \mathrm{~K}$ of RAM. In 1996, as we were beginning to face expectations from our clientele that "everything" would soon be digitized and available over the Internet, I insisted that rare book rooms give up their card catalogs once 
and for all and that archives start putting their finding aids online (Encoded Archival Description version 1.0 was released, not long thereafter, in 1998). In retrospect, those were simple days.

I never could have imagined 2008. At this juncture I find myself wondering how much progress we've made toward those as-yet elusive goals of making both our metadata and our collections universally digital and freely accessible to our global public. Alice Prochaska, whose presentation was transformed into a paper in this issue, noted that we have, however, made excellent progress toward asking the right questions and developing appropriate tools, as the preconference amply demonstrated. Karen Calhoun quoted Thomas Edison as having said "Every method discarded is one step forward." 1 Please consider these gentle commandments in that positive spirit.

\section{Embrace the technological continuum of the book.}

Advances in technology are nothing new in the history of books and archives. What I find notable is that, as the future has continued to unfold, each change in technology has resulted in improvements in both the accessibility of rare materials and the economic sustainability of the production enterprise.

Consider the impact that the following transitions must have had on how our noble predecessors did their jobs. Stone and clay were difficult to inscribe and transport; papyrus, vellum, and paper were much easier to take to bed and to produce in quantity — and they consumed far less space. When the scroll became the codex, libraries had to completely retool to store this new format. When printing was invented, pushing aside the exacting production of magnificent manuscripts, surely the newfangled printed books seemed dull, dull, dull—while, at the same time, one hopes, technologically fascinating to those who looked beyond.

As printing developed, pages and bindings also came to be beautiful; but, inevitably, handcrafted letterpress was replaced by the efficient, but decidedly pedestrian, industrially printed page. Meanwhile, on the manuscript front, medieval calligraphy and complex "hands" had long ceased to be the dominant production methodology. Regardless, the arrival of the typewriter and the mimeograph machine presumably were less than inspiring aesthetically. And, to add insult to injury, ordinary people had to learn a machine-based technical skill. On the library front, catalogers lost a big part of their sense of accomplishment with the arrival of Library of Congress cards, copy cataloging, and finally the strict container that is the MARC format.

1. Slides from Karence Calhoun's presentation are available online at www.slideshare.net/amarintha/calhoun-rbms-rev-june-2008 (Accessed March 13, 2009). 
What replaced craft, beauty, and individuality? Affordability. Mass dissemination. Speed. Accessibility. Intelligibility. Innovation. Efficiency. As human beings have increasingly sought democratization of information and knowledge, every step along the book's technological continuum has served these needs.

In the digital age, we have moved from physical artifacts to intangible content for the first time: an enormous leap, and one that sometimes makes us question whether we are still doing the work that we set out to do in our younger days. Read on.

\section{Rediscover yourself.}

As we spend less time each day handling those beloved physical artifacts, it seems useful to revisit why we love our work and what we bring to it. What is our inherent skill set as librarians and archivists who understand primary materials, and how do those skills translate to the digital? What really attracts us to our work? Is physicality more important to us than content?

Speakers at RBMS 2008 noted some of the emotions and attitudes that lurk behind our love for the artifact. Philip Larkin was quoted as comparing magical vs. meaningful values. Susan Allen suggested that we rely too much on the sentimental. Alice Prochaska noted the aristocracy of certain types of rare materials. Do we define ourselves as sentimental aristocrats who believe in magic? The romantic does figure in how we feel about the objects that we care for, but ultimately we are all about the meaning.

We are the content people-we know how to interpret content, no matter what form it takes. We are the permanence people, in contrast to the librarians and information technology experts who neither focus on nor fully understand just how permanent permanence is meant to be. We are the physicality people-we know the history and meaning of the original objects.

\section{Digitize with abandon.}

Rich Szary had a lot to say to RBMS that was new relative to the digitization scenarios to which we've been accustomed. The notion of carefully selected, designed, and interpreted "boutique projects" has rather precipitously fallen out of fashion. This is because we have realized that many of our users have no desire for us to serve as content filters and that we have been able to digitize only a tiny fraction of our holdings due to the expense of doing it "right." So not only must we turn our artifacts into bits and bytes - should we be content with low-quality ones? (Another aside: I discovered in the course of writing this paper that the Microsoft dictionary suggests that "Szary" is actually spelled "scary.") 
The clarion call today is to stop selecting within collections or volumes, stop doing scholars' interpretive work, increase production rates exponentially, and stock up on terabytes of storage. One might think of this as adopting a "wholesale" rather than a "retail" perspective on digital production. Digitization workstations are in use that enable large-scale, efficient camera work, while also permitting safe handling of rare materials.

Wholesale digitization presents big challenges, of course. Can we develop a generalized profile of collections that are not ripe for comprehensive reproduction? Difficult or heterogeneous formats and copyright are two knotty and pervasive issues to be contended with. Also, it has become a norm in our reading rooms that researchers expect to have the ability to use their own digital cameras in order to achieve speedy and cost-free copying of materials, sometimes in high volume. Many special collections and archives are permitting them to do so; others remain cautious. Service is our business. The customer is always right.

\section{Educate yourself.}

We all need baseline knowledge about the application of digital technologies to our work, and we have many options for obtaining it. The audience at RBMS 2008 learned an extraordinary amount about the state of the art in terms of new directions, expectations, technologies, and tools. Relevant conferences are ubiquitous and essential.

Continuing education workshops also are widely available. The Society of American Archivists offers courses in managing electronic records, and the annual conference is replete with relevant sessions. Rare Book School has several courses focused on digital issues. Additional opportunities abound, including via affordable "webinars."

What skills should I look for in hiring new staff to do this work? How do I cost out digitization of a particular collection? How do I start the conversation about preserving and managing the university's institutional records? Should I worry about copying and preserving every 5 -inch floppy disc that arrives with a collection of scholarly papers? Many of us who are already managing special collections and archives will not have to carry out the digital work ourselves, but we must have the confidence to seek answers to such questions, actively participate in the conversation, and exert local leadership.

I am inclined to think that our civilization is going to lose much of fifty years of human history before we adequately address the born-digital dilemma. Let's do our part to minimize that outcome for tomorrow by learning at least enough to be responsible, forward-thinking special collections librarians today. 


\section{Make your work economically sustainable.}

When Donald Waters of the Mellon Foundation was working with CLIR to formulate the "hidden collections" initiative (launched in 2008), he noted that he had been feeling "nickel-and-dimed to death" by boutique digitization projects. I noted earlier that boutique is dead; long live economical large-scale projects. Grants agencies, including Mellon, CLIR, the National Endowment for the Humanities, and others, place a high value on innovative, cost-effective processing and cataloging methodologies.

Karen Calhoun noted the need to "get over item-level description" and get more serious about streamlining cataloging. Our generalist colleagues in libraries have made massive strides in this regard over the past decade or more. Isn't it time we do the same? Archivists generally let go of item-level description at least 25 years ago and have now widely embraced the Greene/Meissner mandate for "more product, less process." 2

Rare book catalogers have inched toward less-full descriptions by including minimal-level record guidelines in Descriptive Cataloging of Rare Materials, ${ }^{3}$ but does the rather conservative approach that they have articulated to date go far enough?

Digital library systems are beginning to enable collective metadata for digital objects. The Smithsonian's Museum of American Art, for example, has developed software that enables folder-level descriptions linked to digital images of the items in that folder, smoothly implemented in the course of digitization. We will see more and more such systems, and they will come quickly. This is very good news.

\section{Follow the archivists' lead.}

As mentioned above, archivists have moved forward proactively to make their work more sustainable. Simplification of physical processing and description is significantly reducing costs. ("Do you Greene/Meissner your processing?" we ask each other.) Collective description of digital materials is beginning to take hold. Archivists have embraced the mandate to become educated about born-digital records. The archives profession has much farther to go in each of these areas; what is important is that they have proactively begun to take important necessary steps.

Are there parallels that we can identify and implement on the rare books and special collections side of the house? Surely the answer is yes.

2. Mark A. Greene and Dennis Meissner, "More Product, Less Process: Revamping Traditional Archival Processing," American Archivist 68 (2005): 208-63.

3. Descriptive Cataloging of Rare Materials (Books) (Washington, D.C.: Library of Congress, 2007). 


\section{Be promiscuous with your metadata.}

Karen Calhoun's paper, in which she brought preconference attendees up to speed on trends in the broader bibliographic world, offered a perspective that was no less than appalling to some in the audience. Regardless, she is correct to assert that the nature of metadata - in terms of both what our users want and what we can reasonably afford to produce-is undergoing a sea change that we reject at our peril.

The Library of Congress' "bibliographic futures report" calls attention to the need to focus new levels of resources on special collections cataloging: "Transfer value to higher-value activity: In particular, expand the possibilities for knowledge creation by exposing to more users rare and unique materials in libraries that are currently hidden from view and, consequently, underused." 4

Once we have responded to that welcome challenge and created all this metadata, it is paramount that we ensure its easy discoverability. Increased emphasis is being paid to enabling archival finding aids to be "Googleable." Several RBMS speakers noted that we must get our data out of "library silos" and into the environments where most users do their searching, to be where the user is.

OCLC's open-access Worldcat.org interface makes the 135,000,000 MARC records in WorldCat globally accessible, including to those who have no access to subscription searching. While WorldCat itself is somewhat of a silo (a situation that OCLC very actively works to improve), open access to its complete content has been a major step in the right direction.

On the scarier side, Calhoun reported that, in general, users are not interested in structured subject searching. Indeed, Worldcat.org relies principally on open keyword searching, as do most finding aid systems. If structured searching is to become decreasingly available in our systems, we must first make specific special collections-oriented arguments for what types of data are most important to retain (avoiding the knee-jerk retort "all of it") and then make the most out of the hand that we are ultimately dealt. Do we want to suck lemons or make lemonade?

Finally, we must make digitized content and its associated metadata available in ways that encourage and enable its reuse, such as by making it available for harvesting into federated platforms and enabling students and scholars to incorporate it selectively into their own integrated research products.

4. On the Record: Report of the Library of Congress Working Group on the Future of Bibliographic Control (2009): 2, available online at www.loc.gov/bibliographic-future/news/lcwg-ontherecord-jan08-final.pdf (Accessed March 13, 2009). 


\section{Collaborate, collaborate, collaborate.}

Our profession has come a long way from the former isolation of dark and dusty, little-used rare book rooms and archives. We are increasingly out in the open, actively promulgating use of our materials for whatever purposes people find constructive and interesting. Another stage in eliminating any remaining isolation is to actively identify collaborators in all possible endeavors, both within and beyond our home institutions. The days of going it alone are long gone.

In the context of digitization projects, special collections staff often need not bear lead responsibility. We must be at the table when our materials are being incorporated, but technologists, digital library experts, interface designers, metadata experts, and others are key participants. We must learn from them while we help them learn from us (and no whining about how they don't understand us).

Whether in a campus environment or a specialized research library, we also must actively collaborate with scholars in the development of digital tools, resources, and discovery systems. Digital humanities centers are taking center stage, and grants agencies highly value proposals that feature players from professional, scholarly, and technical areas of expertise. Together we can build large scholarly information environments to aggregate our growing universe of scholarly digital assets.

\section{Revere the innovative ideas of the young.}

Karen Calhoun referred to "digital natives"-those who are young enough that the digital world has existed longer than they have. They have no need to adapt or learn new skills; their world is digital. The younger professionals now launching careers in special collections pre-date the future wave of digital natives; nevertheless, they too gravitate toward digital solutions for both communication and tools.

Listen to what excites them. Learn to speak their language. They are joining our corner of the library profession because they love the "stuff"; at the same time, an attraction to the latest technological tools comes to them naturally. I find it thrilling that the plenary hall is increasingly filled with twenty- and thirtysomethings at each successive RBMS preconference. Many of us may be graying, but the newbies are here to save our collections and to take their use to new heights.

One last aside, recalling the Microsoft dictionary (as I did with regard to the scary Mr. Szary): "blogging" has not yet made it in. This is shameful. 


\section{Proactively define our collective future.}

Thanks to UCLA University Librarian Gary Strong's introductory remarks to RBMS 2008 when he proclaimed "This is our time," that statement became the preconference mantra. Let's embrace it and capitalize on the attention currently being paid to us by major players such as the Association of Research Libraries, the Mellon Foundation, the Library of Congress, the Council on Library and Information Resources, OCLC, and many others.

It is not "our time" because our collections are awe-inspiring, beautiful, fragile, and tangible; that is nothing new. It is because democratizing technologies have created new audiences, and new demands from old audiences, to enable them to use what we preserve, easily and remotely. We must respond to that challenge with all the creativity that we, and the energetic successors who are nipping at our heels, can muster.

For archivists who manage contemporary institutional records, the born-digital freight train is no longer on the horizon - it has pulled into the station. How can those of us who curate contemporary private manuscript collections think ahead to plan for the arrival of born-digital materials so that we're prepared to unload the train when it arrives in our stations? How can we educate future creators of collectible collections about how to manage their electronic files so that born-digital manuscripts won't be dead on arrival when they reach our repositories? How will our cataloging, processing, and preservation methodologies have to change to accommodate this material? Once again, let's learn from the archivists. For those who may not yet have begun developing archival skills to complement expertise with books, now is your time.

In addition to the guaranteed onslaught of the born digital, and the obvious challenges of digitizing the physical, can we proactively anticipate and influence what special collections will be in the future?

Book collections are on my mind when I ponder this question. As we strive to tap increasingly tight funding sources to meet the demands of the digital, how much of the physical can we afford to preserve, both retrospectively and prospectively? Should we be placing a higher premium on unique archival collections rather than continuing to give iconic status to every locally unique copy of every book? Should we be defining responsible collections management for rare books, beyond our traditional preservation-oriented practices? If we do not, how long can we stave off being told how to solve space problems, especially when some university collections hold thousands of fairly ordinary books that are unlikely to have a local audience? In terms of the existing dispersal of related materials, some of which live in illogi- 
cal homes, how can we collaborate nationally to enable scholars to work productively without traveling incessantly? (I do not pretend, by the way, that similar questions don't apply equally to archives.)

Of which types of born-digital materials should we become the custodians? Organizational and personal Web sites contain the type of "archival" content that we have always collected and curated, but under what circumstances should the knowledge and interpretive skills that we have be the determining factor for the custodial "location"?

The digital world is here to stay. It shall not pass. More and more, our artifact-oriented business will be pervaded by the virtual. If we insist on maintaining principal allegiance to the physical book, the physical manuscript, and the physical print, we will increasingly become curators of obsolete artifacts to be admired rather than used.

It may be that I was subliminally drawn to the information business while watching Star Trek as a kid and being in awe of the information network on the Starship Enterprise: type type type, and the crew could search and retrieve everything the human race had ever known on a topic. We could never see the computer screen on our TV sets, but perhaps it was displaying gorgeous digital reproductions of originals.

Our job is to make sure that, back home on earth, the artifacts remain available to be used by those who need them, properly exploited, and fully appreciated, and that they continue to exude their magic and provide what plenary speaker Matthew Fisher, of UCLA's Department of English, called the "exquisite sensory experience." But, at the same time, to make sure they remain available, from great distances, to the interplanetary audience of the future.

INDEX TO ADVERTISERS




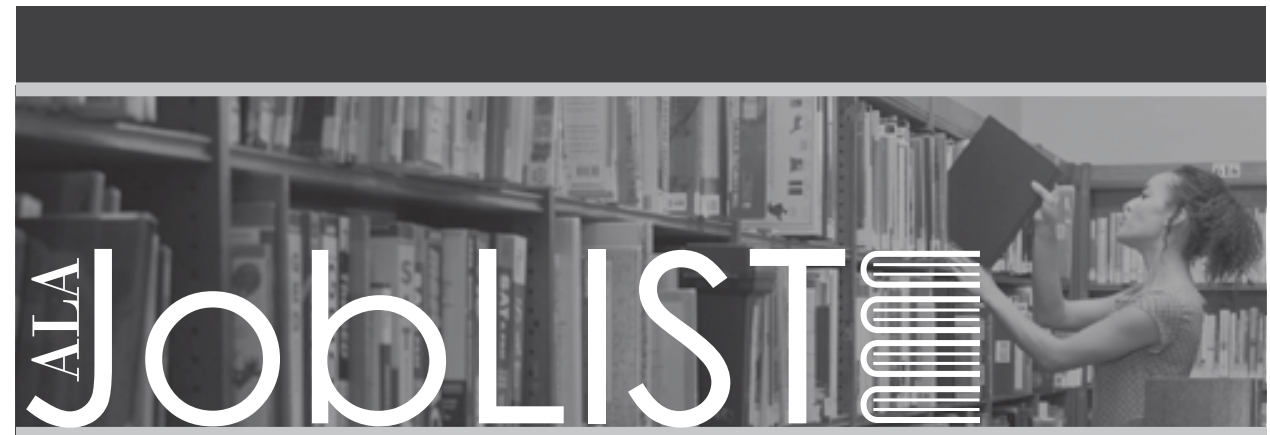

\section{The \#1 source for jobs in \\ Library and Information Science and Technology}

Where Job Seekers and Employers Find Results

\section{Job Seekers}

- Simplify your search-free onestop job-hunting and career advice

- Search hundreds of job ads by employer, library type, location, salary range, and more, including position types like preservation and special collections

- Save your search as an RSS feed to alert you when new jobs matching your requirements become available

- Post your résumé for employers

\section{Employers}

- Strengthen your candidate pool by reaching the profession's most engaged members

- Simplify recruitment-onestop advertising for online and print in C\&RL News and American Libraries

- Review posted résumés

- Connect with candidates

- Discounts available-see ad rates on site for details

\section{One Web site. Far-reaching results. http://JobLIST.ala.org}

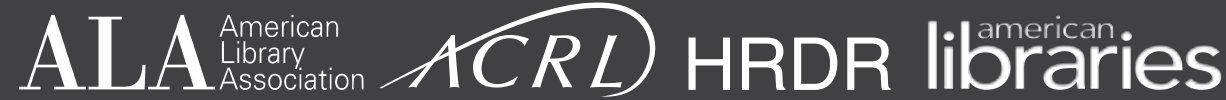
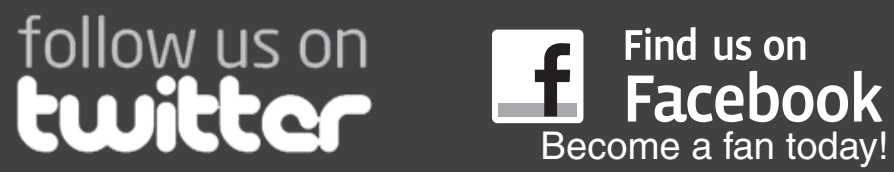